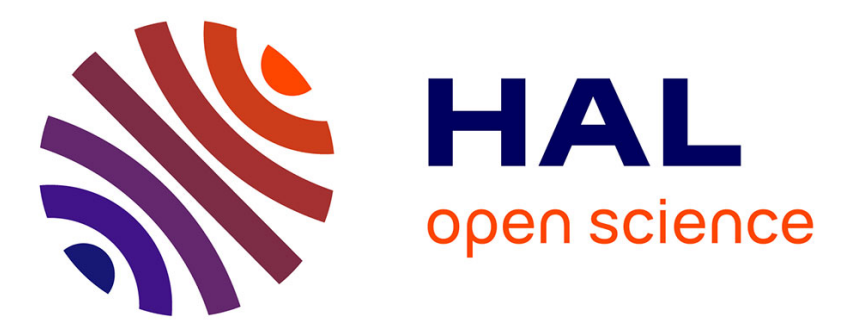

\title{
Americium isotope analysis by Thermal Ionization Mass Spectrometry using the Total Evaporation Method
}

\author{
Alexandre Quemet, Alexandre Ruas, Vincent Dalier, Cédric Rivier
}

\section{To cite this version:}

Alexandre Quemet, Alexandre Ruas, Vincent Dalier, Cédric Rivier. Americium isotope analysis by Thermal Ionization Mass Spectrometry using the Total Evaporation Method. International Journal of Mass Spectrometry, 2018, 431, pp.8-14. 10.1016/j.ijms.2018.05.017 . cea-03470762

\section{HAL Id: cea-03470762 https://hal-cea.archives-ouvertes.fr/cea-03470762}

Submitted on 8 Dec 2021

HAL is a multi-disciplinary open access archive for the deposit and dissemination of scientific research documents, whether they are published or not. The documents may come from teaching and research institutions in France or abroad, or from public or private research centers.
L'archive ouverte pluridisciplinaire HAL, est destinée au dépôt et à la diffusion de documents scientifiques de niveau recherche, publiés ou non, émanant des établissements d'enseignement et de recherche français ou étrangers, des laboratoires publics ou privés. 


\title{
Americium isotope analysis by Thermal Ionization Mass Spectrometry using the Total Evaporation Method
}

\author{
Alexandre Quemet ${ }^{1 *}$, Alexandre Ruas ${ }^{2}$, Vincent Dalier $^{1}$ and Cédric Rivier ${ }^{1}$ \\ ${ }^{I}$ CEA, Nuclear Energy Division, Research Department on Mining and Fuel Recycling \\ Processes, SA2I/LAAT, F-30207 Bagnols sur Cèze, France \\ ${ }^{2}$ Onsite Laboratory Team | Nuclear Material Laboratory | Office of Safeguards \\ Analytical Services | Department of Safeguards |International Atomic Energy Agency
}

\begin{abstract}
In this paper, a simple analytical procedure was developed to measure americium isotope ratios and concentration with high accuracy. The method was tested during the participation in a round robin test organized by the Analytical Methods Committee of the French Atomic Energy Commission. The measurements were performed by Thermal Ionization Mass Spectrometry using the total evaporation method, which is a reference technique for determining actinide isotopic compositions. Expanded uncertainties were estimated at $0.1 \%$ and $0.8 \%$ for the ${ }^{241} \mathrm{Am} /{ }^{243} \mathrm{Am}$ isotope ratio and the Am concentration, respectively. Compared to the assigned value, biases below $0.0001 \%$ and $0.02 \%$ were calculated for the ${ }^{241} \mathrm{Am} /{ }^{243} \mathrm{Am}$ isotope ratio and the Am concentration, respectively.
\end{abstract}

\section{Keywords}

TIMS; Americium; isotope ratio; total evaporation; isotope dilution 


\section{Introduction}

Americium is produced in nuclear reactors from plutonium and is one of the minor actinides. Americium has three isotopes with half-lives above one year: ${ }^{241} \mathrm{Am}$ (432.6(1.2) years, $\mathrm{k}=2),{ }^{242 \mathrm{~m}} \mathrm{Am}(143(4)$ years, $\mathrm{k}=2)$ and ${ }^{243} \mathrm{Am}(7367(46)$ years, $\mathrm{k}=2)$ [1]. ${ }^{241} \mathrm{Am}$ is produced by the beta decay of ${ }^{241} \mathrm{Pu} .{ }^{242 \mathrm{~m}} \mathrm{Am}$ is produced by ${ }^{241} \mathrm{Am}$ neutron capture. ${ }^{243} \mathrm{Am}$ is produced by ${ }^{242} \mathrm{Pu}$ neutron capture followed by beta decay. In spent nuclear fuel, americium is one of the major contributors to waste long-term radiotoxicity, once the plutonium has been removed. Separating americium from other minor actinides is necessary to reduce the volume and the storage period of the nuclear waste for safe disposal in a geological repository [2]. The ${ }^{241} \mathrm{Am}$ isotope is responsible for most of the residual decay heat after one century. The measurement of the americium isotope abundances and concentrations are of prime interest for the management of nuclear wastes, for environmental monitoring and for the surveillance of the historical radioactive fallout on site [3]. Also, nuclear data determination (such as half-life of ${ }^{243} \mathrm{Am}$, neutron calculation codes qualification to understand physical phenomena in nuclear reactors or transmutation studies) requires isotope ratio determination with low uncertainty, typically lower than $0.1 \%[4,5]$. The ${ }^{241} \mathrm{Am}$ analysis is also important for safeguards and nuclear forensics as it acts as a clock for plutonium separation, ${ }^{241} \mathrm{Am}$ being a descendant of ${ }^{241} \mathrm{Pu}$. Therefore, its accurate analysis can give some evidence about the origin of a nuclear sample and the different processes undertaken.

TIMS is a reference technique for actinide isotope measurement to obtain isotope ratios with high accuracy (measurement trueness and precision) [6-9]. Another advantage of TIMS analyses is the possibility to perform concentration determination by isotope dilution (ID-MS) with low uncertainty, lower than $1 \%$ [10-12]. TIMS is frequently used for actinides isotope composition determination [6,7,13-18], in particular for uranium and plutonium [4,5,8,19-22]. On the other hand, americium metrological isotope analysis are rare, due to the lack of Certified Reference Material (CRM) [5]. The CRM scarcity limited the americium measurement accuracy at about $0.5 \%$ and render the method evaluation with TIMS difficult. However, TIMS has the potential to determine americium isotope ratio with an accuracy lower than $0.1 \%$. 
The total evaporation method is a TIMS reference method for measuring major isotope ratios $[18,23]$. This method was developed to compensate for isotope fractionation, leading to an accuracy improvement and has been successfully applied to actinide isotopic measurements $[6,7,15]$. This method also allows for a decrease in the quantity of analyte: according to Dubois et al., the sample amount for an analysis using the total evaporation method is between 20 to 50 times less than using conventional measurement techniques $[6,7,17,24]$. Also, using higher resistance amplifiers or electron multipliers improves the sensitivity on minor isotopes and sometimes the accuracy [6,25-28].

Considering the lack of americium CRM and ID-MS spike solution, the Analytical Methods Committee (CETAMA) of the French Atomic Energy Commission (CEA) and the Joint Research Centre of the European Commission (EC-JRC) produced an americium $\mathrm{CRM}$ with a high ${ }^{243} \mathrm{Am}$ isotope abundance. A round robin test (RRT) was organized by the CETAMA in order to verify the certified values and evaluate the laboratories' performances for americium isotope ratio and concentration measurements. The present study investigates the accuracy of americium concentration measurement by ID-MS and americium isotope measurement by the total evaporation method using the CRM produced by EC-JRC and CETAMA, and by comparing our results with the assigned values (provided to us afterwards).

\section{Experimental}

\subsection{Materials, reagents, certified reference materials and sample}

All solutions were prepared using polypropylene vials, except for the americium solutions, which were prepared in PFA vials. 3 mol.L $\mathrm{L}^{-1}$ nitric acid solutions were prepared by diluting high purity nitric acid (Merck, Suprapur) with deionized water (resistivity: 18.2 M $\Omega . \mathrm{cm}$ ). A high precision balance (Mettler-Toledo, WXTP 205) was used to prepare all the solutions.

Analytical method validation for the RRT sample americium isotope determination was performed on the IRMM 49d CRM provided by the EC-JRC. More details about using a 
plutonium CRM to validate a method designed to measure americium are given in section 2.4.2. The IRMM 49d is certified for the ${ }^{240} \mathrm{Pu} /{ }^{242} \mathrm{Pu}$ isotope ratio: $0.046070(35)(\mathrm{k}=2)$. The plutonium isotope ratio determined in this study was updated at the certified date of the CRM (2010/07/01) to correct for the radioactive decay using the half-lives of ${ }^{240} \mathrm{Pu}$ (6561(14) years, $\mathrm{k}=2)$ and ${ }^{242} \mathrm{Pu}(373000(6000)$ years, $\mathrm{k}=2)$ [1].

Analytical method validation for the ${ }^{243} \mathrm{Am} /{ }^{241} \mathrm{Am}$ isotope ratio determination when it is close to 1 (optimum isotope ratio for the concentration determination by isotope dilution) was performed on the U500 CRM provided by the National Institute of Standard and Technology (NIST). More details about using a uranium CRM to validate a method designed to measure americium are given in section 2.4.2. This solution is certified for the ${ }^{235} \mathrm{U} /{ }^{238} \mathrm{U}$ isotope ratio: 0.9997(10) $(\mathrm{k}=2)$.

The americium spike solution $\left({ }^{241} \mathrm{Am} 100\right.$ at $\%$ ) was provided by the Henri Becquerel National Laboratory. This solution is certified for an americium activity of $1686(12) \mathrm{kBq} . \mathrm{g}^{-}$ ${ }^{1}(\mathrm{k}=2)$ corresponding to $13.29(10) \mu \mathrm{g} \cdot \mathrm{g}^{-1}(\mathrm{k}=2)$ at the certification date $(2003 / 10 / 16)$. This concentration was updated at the date of use in order to correct the ${ }^{241}$ Am radioactive decay using the half-life of ${ }^{241} \mathrm{Am}(432.6(1.2)$ years, $\mathrm{k}=2)$ [1].

The developed methodology was tested during the RRT organized by the CETAMA. The laboratory received a sealed vial containing $3.5 \mathrm{~mL}$ of solution (hereafter referred to as sample solution). The solution characteristics provided by the CETAMA were: americium concentration around $1.5 \mu \mathrm{g} . \mathrm{g}^{-1},{ }^{243} \mathrm{Am}$ isotope abundance around $88 \%,{ }^{241} \mathrm{Am}$ isotope abundance around $12 \%$ and nitric solution acidity around $1 \mathrm{M}$. The vial contained about $5 \mu \mathrm{g}$ of americium. The americium istope ratios determined in this study were updated on $2017 / 01 / 01$ in order to correct the radioactive decay with the half-lives of ${ }^{241} \mathrm{Am}$ (432.6(1.2) years, $\mathrm{k}=2),{ }^{242 \mathrm{~m}} \mathrm{Am}(143(4)$ years, $\mathrm{k}=2)$ and ${ }^{243} \mathrm{Am}(7367(46)$ years, $\mathrm{k}=2)$ [1].

\subsection{Instrumentation}

\subsubsection{Thermal Ionization Mass Spectrometry}


Isotope measurements were performed on two TIMS equipped with a glove box: a VG Sector 54 and a Thermo Scientific Triton. Each TIMS has a low resolution magnetic field sector (resolution about 400). The measurements were performed in multi-collection and positive modes. Intercalibration gains of the Faraday cup detectors were measured regularly by an automated process implemented on the TIMS software.

The VG Sector 54 TIMS is equipped with 9 movable Faraday cups with high-ohmic resistors $\left(10^{11} \Omega\right)$. A triple Re-filament configuration was used to control independently the evaporation and the ionization temperature.

The Thermo Scientific Triton TIMS is equipped with 9 movable Faraday cups which can be coupled to $10^{11} \Omega$ current amplifiers (9 available and hereafter referred to as FC 11) or a $10^{12} \Omega$ current amplifier ( 1 available and hereafter referred to as FC 12), one fixed discrete dynode Secondary Electron Multiplier (hereafter referred to as SEM), located behind the central Faraday cup, and 3 movable continuous dynode electron multipliers operated in ion counting mode. The SEM is combined with a high abundance filter ("Retarding Potential Quadrupole"-RPQ) to improve the abundance sensitivity to about $10 \mathrm{ppb}$ at mass $\mathrm{M}$ compared to mass $\mathrm{M}+1$ or $\mathrm{M}-1$. A double Re-filament configuration was used to control independently the evaporation and the ionization temperature.

VG Sector 54 and Triton filaments (Re metal, purity $99.99 \%$ ) are provided by ATES (France). The deposition procedure was similar for both TIMS. $1 \mu \mathrm{L}$ of solution was deposited onto the filament. After deposition, the sample preparation was dried with a $0.5 \mathrm{~A}$ current. Then the current was increased progressively to $2 \mathrm{~A}$ in $10 \mathrm{~s}$.

Different analyses were performed to determine the ${ }^{241} \mathrm{Am} /{ }^{243} \mathrm{Am}$ and the ${ }^{242 \mathrm{~m}} \mathrm{Am} /{ }^{243} \mathrm{Am}$ isotope ratios:

- 4 analyses were conducted using the VG Sector 54 TIMS. The ${ }^{241} \mathrm{Am},{ }^{242 \mathrm{~m}} \mathrm{Am}$ and ${ }^{243} \mathrm{Am}$ isotopes were collected on FC 11 . However, the results obtained on the ${ }^{242 \mathrm{~m}} \mathrm{Am} /{ }^{243} \mathrm{Am}$ isotope ratio were inconclusive due to the lack of signal at mass 242 : the measured signal (about $200 \mu \mathrm{V}$ ) is too close to the Faraday cup detection limit. 
The Faraday cup detection limit can be estimated as 3 times the standard deviation of the Johnson-Nyquist noise (around $120 \mu \mathrm{V}$ ) [25].

- 13 analyses were performed using the Triton TIMS. Among the 13 analyses, 9 analyses were performed using FC 12 to collect the ${ }^{241} \mathrm{Am}$ isotope, the SEM to measure the ${ }^{242 \mathrm{~m}} \mathrm{Am}$ isotope and a FC 11 to detect the ${ }^{243} \mathrm{Am}$ isotope. The 4 other analyses were performed with the FC 12 to collect the ${ }^{241} \mathrm{Am}$ isotope and a FC 11 to measure the ${ }^{242 \mathrm{~m}} \mathrm{Am}$ and ${ }^{243} \mathrm{Am}$ isotopes.

\subsubsection{SEM optimization}

The SEM detector was used for the ${ }^{242 \mathrm{~m}}$ Am isotope measurement on the Triton TIMS. It required dark noise measurement and SEM/FC inter-calibration gain (or yield) determination.

The SEM dead time was implemented by the manufacturer and set at 24 ns.

The dark noise was measured with the isolation valve closed before each half day of measurements. Each dark noise measurement took about 10 minutes. A dark noise level lower than $9 \mathrm{cpm}$ (count per minute) was observed for the SEM.

The SEM/FC inter-calibration gain (or yield measurement) was performed with the method implemented within the TIMS software by measuring an ion beam of $5 \mathrm{mV} 10$ times during 5 minutes on the central Faraday cup connected to a $10^{11} \Omega$ current amplifier and the SEM

alternatively. The yield measurement was performed on the ${ }^{187} \mathrm{Re}$ isotope, coming from the ionization filament, in order to obtain a very stable signal [29]. The yield was calculated according to Equation (1):

$$
\operatorname{Yield}(\%)=\frac{I_{S E M}}{I_{F C} / 1.60217733 \times 10^{-8}} \times 100
$$

With ISEM the ion beam intensity obtained with the SEM (in count per second or cps) and $\mathrm{I}_{\mathrm{FC}}$ the ion beam intensity obtained with the Faraday cup (in V). 
The uncertainties associated with the inter-calibration procedure (the yield depends on the atomic number [30]), dead time, non-linearity behavior and drift in the SEM efficiency were included in the ${ }^{242 \mathrm{~m}} \mathrm{Am} /{ }^{243} \mathrm{Am}$ isotope ratio uncertainty estimation [31].

Several inter-calibration gains were measured for the SEM. All of them were within $95.5 \pm 1.0 \%$ (see Table S1 in supplementary information). The measurement was corrected by the average of the yields determined before and after each measurement in order to minimize the impact of the detector yield variation on the analysis. The detector voltage, which has an impact on the SEM performance and the detector lifespan, was unchanged during this study (2040 V).

\subsubsection{Isotope analysis method}

All the isotope measurements were performed with the total evaporation method. This method is based on the collection of the sample ionized isotopes until its full consumption. The total evaporation method used in this study was previously described for others elements and was modified for americium [6,7,12]. Once the ionization filament was heated up to $5.2 \mathrm{~A}$, the evaporation filament was heated to obtain a ${ }^{243} \mathrm{Am}^{+}$ion beam of low intensity $(1 \mathrm{mV})$, but enough to perform a "Peak center" (mass calibration and ions beam centering in the detector) and lenses optimization. The data acquisition started after the electronic baselines acquisition. The evaporation filament current was controlled in order to keep the americium ion beam constant $(1.5 \mathrm{~V}$ with the Triton and $3 \mathrm{~V}$ with the VG Sector 54 for ${ }^{241} \mathrm{Am}$ and ${ }^{243} \mathrm{Am}$ intensity sum). The integration times were $0.131 \mathrm{~s}$ and $1 \mathrm{~s}$ for Triton and VG Sector 54, respectively. An analysis example on the Triton showing the ${ }^{241} \mathrm{Am},{ }^{242 \mathrm{~m}} \mathrm{Am}$ and ${ }^{243} \mathrm{Am}$ isotope signal variation on the FC 12, SEM and FC 11, respectively, is presented in Fig $\mathrm{S} 1$ in the supplementary information. The acquisition times were around $20 \mathrm{~min}$ (about 9000 cycles) for the Triton TIMS and around $5 \mathrm{~min}$ (about 300 cycles) for the VG Sector 54 TIMS. The total cumulated signals were around $13000 \mathrm{~V}$ and $560 \mathrm{~V}$ for the Triton and VG Sector 54 TIMS, respectively. The interpretation of the total cumulated signal for both TIMS need to be done carefully as the integration time and the target intensity are different. When the evaporation filament current reached a maximum value of $6 \mathrm{~A}$ and the ion beam intensity decreased down to $10 \mathrm{mV}$, the data 
acquisition was ended. The total evaporation method was also applied to uranium and plutonium during the method validation.

All the experiments (CRM and RRT sample analyses) were performed with about $100 \mathrm{ng}$ of analyte (U, Pu or Am) quantity deposited onto the filament. The sample initial solution had an americium concentration (around $1.5 \mathrm{ng} . \mu \mathrm{L}^{-1}$ ) too low for direct analysis. A concentration step was required: $1.4 \mathrm{~mL}$ of the sample was dried and re-dissolved in $20 \mu \mathrm{L}$ of nitric acid. This solution had an americium concentration close to $100 \mathrm{ng} \mu \mathrm{L}^{-1}$.

\subsection{Concentration determination by isotope dilution}

The americium concentration was determined by isotope dilution (Equation (2)).

$$
[A m]_{S}=[A m]_{T} \times \frac{m_{T}}{m_{S}} \times \frac{M_{S}}{M_{T}} \times \frac{(241)_{T}}{(243)_{S}} \times \frac{(243 / 241)_{M i x}-(243 / 241)_{T}}{1-(243 / 241)_{M i x} \times(241 / 243)_{S}}
$$

Where $\mathrm{T}$ refers to the tracer, Mix refers to the sample tracer mixture and $\mathrm{S}$ refers to the sample; $\mathrm{m}$ are the masses involved in the mixture, $\mathrm{M}$ are the atomic weights, (241) and (243) are the isotope abundances (atom \%), 243/241 and 241/243 are the isotope ratios.

First, two diluted spike solutions around $1 \mu \mathrm{g} . \mathrm{g}^{-1}$ (hereafter referred to as diluted spike-1 and diluted spike-2) were prepared gravimetrically from the initial americium spike solution ${ }^{241} \mathrm{Am} 100$ at\%. Then, sample diluted spike-1 mixtures (2 mixtures) and samplediluted spike-2 mixtures (5 mixtures) were prepared by weight. Each mixture was evaporated after preparation, and then re-dissolved in $6 \mu \mathrm{L}$ nitric acid. $1 \mu \mathrm{L}$ (about $100 \mathrm{ng}$ of Am) of this solution was deposited onto a filament. The ${ }^{241} \mathrm{Am} /{ }^{243} \mathrm{Am}$ isotope ratio was analyzed with the total evaporation method. The ${ }^{241} \mathrm{Am} /{ }^{243} \mathrm{Am}$ isotope ratio of the mixtures was close to 1 . In practice the ${ }^{241} \mathrm{Am} /{ }^{243} \mathrm{Am}$ isotope ratios range from 0.9 to 1.1 . The ${ }^{241} \mathrm{Am}$ and ${ }^{243} \mathrm{Am}$ isotopes were collected on FC 11.

\subsection{Results evaluation and uncertainties estimation}

\subsubsection{Results evaluation}


The bias was calculated with the equation (3).

$$
\text { Bias }(\%)=\frac{Z-r e f}{r e f} \times 100
$$

Where $\mathrm{Z}$ is the experimental value and ref is the reference value of the CRM used to evaluate the method trueness.

The precision of the analysis series was evaluated by computing the Relative Standard Deviation (RSD) of all the measurements.

\subsection{2. ${ }^{241} \mathrm{Am} /{ }^{243} \mathrm{Am}$ isotope ratio uncertainty}

The ${ }^{241} \mathrm{Am} /{ }^{243} \mathrm{Am}$ isotope ratio uncertainty $(\mathrm{u}, \mathrm{k}=1)$ is estimated using equation (4) [32]:

$$
\begin{gathered}
\frac{u^{2}\left(\frac{{ }^{241} A m}{{ }^{243} A m}\right)}{\left(\frac{{ }^{241} A m}{{ }^{243} A m}\right)^{2}}=\frac{u^{2}(\bar{x})}{\bar{x}^{2}}+\frac{u^{2}(\text { trueness })}{(\text { trueness })^{2}}+\frac{u^{2}(\text { ref })}{(\text { ref })^{2}} \\
\frac{u(\text { trueness })}{\text { trueness }}=\frac{\text { Maximum bias on } C R M}{\sqrt{3}}
\end{gathered}
$$

The two main components of Equation (4) are: the measurement precision component (first term) and the systematic error component (second and third term). The first term of equation (4) takes into account the uncertainty due to random effects such as the operator (the measurements were performed by two different operators) or the instrument (the measurements were performed on two different TIMS). This term is given by the RSD of all the measurements. It is important to note that the Faraday cup inter-calibration gain (uncertainty around $3 \mathrm{ppm}$ ) and the background correction can be considered as negligible in comparison to the measurement precision [33]. The measurement trueness is calculated using Equation (5) and is, ideally, determined using a CRM of the same element with a similar isotope ratio as the sample. At the time of this study (i.e. before the result of the 
RRT where divulgated) no americium CRM was available. In order to find an analogous CRM, different criteria were considered by following importance order: similar isotope ratio, similar ionization potential, similar analyzed masses, and similar masses gap between the two isotopes. So, as a first approach, the ${ }^{240} \mathrm{Pu} /{ }^{242} \mathrm{Pu}$ isotope ratio of the IRMM $49 \mathrm{~d}$ CRM was used to evaluate the method measurement trueness developed to determine the ${ }^{241} \mathrm{Am} /{ }^{243} \mathrm{Am}$ isotope ratio in the sample. This plutonium CRM was chosen because: the isotope ratios are similar $(0.046070$ for the IRMM 49d CRM and around 0.136 for the sample), plutonium is close to americium in the Mendeleev classification, their first ionization potentials are very close (6.06 eV for $\mathrm{Pu}$ and $5.99 \mathrm{eV}$ for $\mathrm{Am}$ [34]), the masses involved and the masses gap between ${ }^{241} \mathrm{Am} /{ }^{243} \mathrm{Am}$ and ${ }^{240} \mathrm{Pu} /{ }^{242} \mathrm{Pu}$ are very close. When the ${ }^{241} \mathrm{Am} /{ }^{243} \mathrm{Am}$ isotope ratio was close to 1 (for the sample-tracer mixture in the isotope dilution methodology), the measurement trueness of the method was estimated using the U500 CRM. This uranium CRM has a ${ }^{235} \mathrm{U} /{ }^{238} \mathrm{U}$ very close to 1 . Moreover, uranium is close to americium in the Mendeleev classification with a similar first ionization potential (6.19 $\mathrm{eV}$ for $\mathrm{U}$ and $5.99 \mathrm{eV}$ for $\mathrm{Am})$ [34]. In the third term of equation (4), $\mathrm{u}(\mathrm{ref})$ corresponds to the CRM isotope ratio uncertainty $(\mathrm{k}=1)$.

The ${ }^{240} \mathrm{Pu} /{ }^{242} \mathrm{Pu}$ and ${ }^{235} \mathrm{U} /{ }^{238} \mathrm{U}$ isotope ratio uncertainties of the IRMM $049 \mathrm{~d}$ and U500 CRM used for the americium method validation were estimated with the same approach as for the ${ }^{241} \mathrm{Am} /{ }^{243} \mathrm{Am}$ isotope ratio (equations 4 and 5).

\subsection{3. ${ }^{242 \mathrm{~m}} \mathrm{Am} /{ }^{243} \mathrm{Am}$ isotope ratio uncertainty}

The ${ }^{242 \mathrm{~m}} \mathrm{Am} /{ }^{243} \mathrm{Am}$ uncertainty was also estimated with a similar approach as for the ${ }^{241} \mathrm{Am} /{ }^{243} \mathrm{Am}$ uncertainty. The measurement trueness was calculated using Equation (5). In this case, our laboratory had no analogous CRM fulfilling the criteria: similar isotope ratio, similar ionization potential, similar masses analyzed and similar masses gap between the two isotopes. The most important criterion being a similar isotope ratio, the maximum bias used in Equation (5) was estimated using the ${ }^{234} \mathrm{U} /{ }^{238} \mathrm{U}$ isotope ratio measurement in natural uranium [7]. ${ }^{234} U / 238 U$ isotope ratio in natural uranium $(\approx 0.000055)$ is close to the ${ }^{242 \mathrm{~m}} \mathrm{Am} /{ }^{243} \mathrm{Am}$ in the sample $(\approx 0.00014)$. The measurement trueness was found to be $0.1 \%$ 
for the ${ }^{234} \mathrm{U} /{ }^{238} \mathrm{U}$ using the total evaporation method for $100 \mathrm{ng}$ of deposited uranium (same deposited quantity as the RRT sample) [7].

However, this measurement trueness (i.e. for ${ }^{234} \mathrm{U} /{ }^{238} \mathrm{U}$ ) is expected to underestimate the bias coming from the peak tailing (TIMS abundance sensitivity) in the case of the ${ }^{242 \mathrm{~m}} \mathrm{Am} /{ }^{243} \mathrm{Am}$ ratio. Indeed, the peak tailing effect varies with the mass gap between the major isotope and the minor isotope. The mass gap between the minor isotope ${ }^{234} \mathrm{U}$ and the major isotope ${ }^{238} \mathrm{U}$ in natural uranium is higher than the one between ${ }^{242 \mathrm{~m}} \mathrm{Am}$ and ${ }^{243} \mathrm{Am}$.

Therefore, a component was added to Equation (4) in order to take into account the uncertainty coming from the peak tailing (Equation (6)). Burger et al. have shown that the peak tailing contribution counts for less than $50 \%$ of the final uncertainty budget for the ${ }^{234} U /{ }^{238} U$ and ${ }^{236} U / 238 U$ isotope ratio measurement [33]. In that study, isotope ratios were measured using the total evaporation method with Faraday cups or using an internal normalization with a combined SEM/Faraday cup analysis. Burger et al. performed measurement on a 235 enriched uranium allowing a good estimation of the peak tailing uncertainty for a mass gap of one between the major $\left({ }^{235} \mathrm{U}\right)$ and the minor $\left({ }^{234} \mathrm{U}\right.$ or $\left.{ }^{236} \mathrm{U}\right)$ isotopes. In our study, a conservative estimate for the peak tailing uncertainty equal to $50 \%$ of the final uncertainty was considered.

$$
\frac{u^{2}\left(\frac{{ }^{242 \mathrm{~m}} \mathrm{Am}}{{ }^{243} \mathrm{Am}}\right)}{\left(\frac{\left.{ }^{242 \mathrm{~m} A m}\right)^{2}}{{ }^{243} \mathrm{Am}}\right)^{2}}=\frac{u^{2}(\bar{x})}{\bar{x}^{2}}+\frac{u^{2}(\text { trueness })}{(\text { truenes })^{2}}+\frac{u^{2}(\text { ref })}{(\text { ref })^{2}}+\frac{u^{2}(\text { peak_tailing })}{(\text { peak_tailing })^{2}}
$$

\subsubsection{Americium concentration uncertainty}

The americium concentration uncertainties were estimated by combining the uncertainties from each term in equation (2). In order to minimize the concentration uncertainty, each term uncertainty in equation (2) was computed carefully. The spike concentration uncertainty is certified by the Henri Becquerel National Laboratory. As the spike is enriched at $100 \%$ in ${ }^{241} \mathrm{Am}$ isotope, the spike isotopic composition has an uncertainty equal to zero. The uncertainties associated with sample isotope ratios were estimated with the 
method described in section 2.4.2. The last parameter affecting the concentration uncertainty is the mixture isotope ratio. The mixtures were prepared in order to obtain a mixture isotope ratio close to 1 , which is the isotope ratio where the best mass spectrometric accuracy is achieved.

\section{Results and discussion}

The round robin test sample was analyzed as an unknown sample. However, at the end of the study, the results were compared to the RRT assigned values, which allowed evaluation of the developed method by estimating accuracy and precision Note that the term 'reference' is only used for the reference value of the IRMM 49d and U500 CRM.

\subsection{Method validation}

\subsubsection{Method validation for the ${ }^{241} \mathrm{Am} /{ }^{243} \mathrm{Am}$ isotope ratio determination in the sample}

The method validation for the ${ }^{241} \mathrm{Am} /{ }^{243} \mathrm{Am}$ isotope ratio measurement in the sample using the total evaporation method was performed using the ${ }^{240} \mathrm{Pu} /{ }^{242} \mathrm{Pu}$ isotope ratio measurement on the IRMM 49d CRM. Three analyses were performed using the Triton TIMS. The ${ }^{242} \mathrm{Pu}$ isotope was collected on a FC 11 and the ${ }^{240} \mathrm{Pu}$ isotope was collected on the FC 12. The results corrected for radioactive decay are summarized in Table 1.

These values are in good agreement with the reference value. The bias obtained is equal to $-0.01 \%$ and the relative standard deviation is below $0.01 \%$. The ${ }^{240} \mathrm{Pu} /{ }^{242} \mathrm{Pu}$ isotope ratio uncertainty is estimated to be $0.08 \%$. In the supplementary information (Fig. S2), the relative contributions of the main sources of uncertainty are shown. The principal source of uncertainty is the CRM accepted isotope ratio uncertainty (about $74 \%$ of the total uncertainty budget). The good results obtained on the CRM IRMM 49d confirm the methodology used to determine the americium isotope ratio in the sample with the total evaporation method. 


\subsubsection{Method validation for the ${ }^{241} \mathrm{Am} /{ }^{243} \mathrm{Am}$ isotope ratio determination close to 1 in the sample-tracer mixture}

In order to confirm the methodology used to determine the ${ }^{241} \mathrm{Am} /{ }^{243} \mathrm{Am}$ isotope ratio close to 1 in the sample-tracer mixture for isotope dilution, two analyses were performed using the total evaporation method on ${ }^{235} \mathrm{U} /{ }^{238} \mathrm{U}$ isotope ratio of the U500 CRM. The measurements were performed on the Triton TIMS. The ${ }^{235} \mathrm{U}$ and ${ }^{238} \mathrm{U}$ isotopes were collected on a FC 11. The results are shown in Table 1.

The obtained bias is equal to $0.04 \%$ and the observed relative standard deviation is equal to $0.01 \%$. The ${ }^{235} \mathrm{U} /{ }^{238} \mathrm{U}$ isotope ratio uncertainty is estimated at $0.11 \%$ and is in compliance with the safeguards international target values $(0.14 \%, \mathrm{k}=2)$ for this uranium enrichment [35]. The principal source of uncertainty is from the CRM accepted isotope ratio uncertainty (about $76 \%$ of the total uncertainty budget, see Fig. S2 in supplementary information). The values are in good agreement with the reference value and confirm the measurement methodology for americium samples in which ${ }^{241} \mathrm{Am} /{ }^{243} \mathrm{Am}$ isotope ratio are close to 1 .

\subsection{Americium sample analysis}

\subsubsection{Isotope ratio measurements}

The results are summarized in Table 2 and in Figure 1 . The ${ }^{241} \mathrm{Am} /{ }^{243} \mathrm{Am}$ isotope ratio is the average of the results obtained with the Triton and VG Sector 54, the ${ }^{242 \mathrm{~m}} \mathrm{Am} /{ }^{243} \mathrm{Am}$ ratio is the results average obtained with the Triton TIMS only using the SEM. The obtained results were compared afterwards with the assigned value provided from the RRT results.

The results obtained for the ${ }^{241} \mathrm{Am} /{ }^{243} \mathrm{Am}$ isotope ratio with the Triton and VG Sector 54 are similar: compared to the assigned value the biases are $-0.00092 \%$ and $0.00040 \%$ for the Triton and the Sector 54, respectively. The RSD are $0.04 \%$ and $0.05 \%$ for the Triton and the Sector 54, respectively. The results average obtained with both TIMS are in good agreement with the assigned value (bias $=0.000090 \%$ ). 
The ${ }^{241} \mathrm{Am} /{ }^{243} \mathrm{Am}$ isotope ratio uncertainty was estimated using the method described in section 2.4 .2 and is $0.11 \%$. The relative contribution of the main sources of uncertainty are shown in the supplementary information (Fig. S2). They are from the CRM uncertainty used for the method validation (about $46 \%$ of the total uncertainty budget) and the measurement precision obtained from the RSD of the 17 determinations using both TIMS (about $42 \%$ of the total uncertainty budget).

Unlike the ${ }^{241} \mathrm{Am} /{ }^{243} \mathrm{Am}$ assigned value, which has been characterized by EC-JRC characterization, the ${ }^{242 \mathrm{~m}} \mathrm{Am} /{ }^{243} \mathrm{Am}$ assigned value is the DerSimonian-Laird weighted mean of the results from all the participating laboratories. At present, the ${ }^{242 \mathrm{~m}} \mathrm{Am} /{ }^{243} \mathrm{Am}$ assigned value is a preliminary value that needs to be considered cautiously. A positive bias of $4.0 \%$ was observed for our ${ }^{242 \mathrm{~m}} \mathrm{Am} /{ }^{243} \mathrm{Am}$ isotope ratio measurements compared to the assigned value. Different experiments carried out on uranium minor isotopes ratios in our laboratory showed that the SEM helped to get a bias below $0.4 \%$ (see Table S2 in supplementary information). These experiments also showed that using the SEM decreases the bias in comparison to a measurement using only Faraday cups thanks to a better sensitivity and the RPQ filter attenuating the abundance sensitivity. These measurements were performed with a mass gap of 1 between the major and the minor isotope. However, the uranium ratios were 40 to 80 times higher than the ${ }^{242 \mathrm{~m}} \mathrm{Am} /{ }^{243} \mathrm{Am}$ ratio, which tends to minimize the abundance sensitivity effect. In the case of the ${ }^{242 \mathrm{~m}} \mathrm{Am} /{ }^{243} \mathrm{Am}$ ratio, the SEM also helped to decrease the bias compared to a measurement using only Faraday cups (bias $=14 \%$ with Faraday cups and bias $=4.0 \%$ with the SEM, see Table S3 supplementary information). However, a bias below $0.4 \%$ was not obtained for the ${ }^{242 \mathrm{~m}} \mathrm{Am} /{ }^{243} \mathrm{Am}$ ratio like for uranium minor isotopes ratios. The SEM yield calibration is also an important uncertainty source, but the SEM calibration protocol was similar for the uranium and americium determination. These observations suggest that the positive bias observed on the ${ }^{242 \mathrm{~m}} \mathrm{Am} /{ }^{243} \mathrm{Am}$ isotope ratio was not completely coming from the abundance sensitivity, the low signal on the SEM due to low isotope abundance or the SEM calibration. Among the 9 laboratories participating in the RRT, 4 laboratories used TIMS and 5 laboratories used ICP-MS. No other information (methods or detectors used) was described in the RRT final report. The values given by the participating laboratories were extremely variable (bias between $-21 \%$ and $44 \%$ ) showing that the assigned value must 
at present be considered with care. The ${ }^{242 \mathrm{~m}} \mathrm{Am} /{ }^{243} \mathrm{Am}$ isotope ratio measurement precision was estimated using the RSD (2.2\%) which was significantly higher than the RSD obtained for the ${ }^{241} \mathrm{Am} /{ }^{243} \mathrm{Am}$ isotope ratio (0.04 \%). It is mostly due to the SEM stability [6]. Finally, the ${ }^{242 \mathrm{~m}} \mathrm{Am} /{ }^{243} \mathrm{Am}$ isotope ratio uncertainty was estimated at $8.9 \%(\mathrm{k}=2)$. It remains in agreement with the assigned value.

\subsubsection{Concentration determination}

The americium concentration of the sample is the average of all the determinations by isotope dilution (equation (2)) described in the section 2.3 (Table 3).

The relative standard deviation obtained on the seven mixtures results is $0.06 \%$. The value found for the americium sample concentration is $1.572 \pm 0.013 \mu \mathrm{g} \cdot \mathrm{g}^{-1}(\mathrm{k}=2)$. The relative uncertainty obtained for the americium concentration is about $0.81 \%$. The relative contributions, expressed in percent, of the main uncertainty sources for the americium concentration in the sample are given in Figure 2. The uncertainty of the spike concentration used is the principal source of uncertainty (about $88 \%$ of the total uncertainty). The americium concentration determined by isotope dilution is in agreement with the certified value: the bias is below $0.02 \%$.

\section{Conclusions}

This study presents a simple analytical method to perform americium isotope determination using the total evaporation method. It was validated through the participation in a round robin test organized by the CETAMA. The total evaporation method is satisfactory for the americium isotope determination: a bias of $0.000090 \%$ was obtained for the ${ }^{241} \mathrm{Am} /{ }^{243} \mathrm{Am}$ isotope ratio with a measurement expanded uncertainty estimated at $0.11 \%$. The ${ }^{242 \mathrm{~m}} \mathrm{Am} /{ }^{243} \mathrm{Am}$ isotope ratio measurement using the total evaporation method was more difficult because of the low abundance of the ${ }^{242 \mathrm{~m}} \mathrm{Am}$. The SEM helped to decrease the bias in comparison to a measurement with a FC thank to the RPQ filter and the sensitivity improvement. 
The TIMS measurements with the total evaporation method combined with the isotope dilution offers the possibility to determine americium concentration with an uncertainty estimation $(\mathrm{k}=2)$ lower than $1 \%$, which is mainly coming from to the spike concentration uncertainty. The americium isotope ratio and concentration determination are in good agreement with the assigned value provided by the CETAMA for the inter-laboratory comparison, which proves our americium isotope measurements and our uncertainty estimation approach to be reliable.

\section{Acknowledgements}

We are grateful to Dr. S. Baghdadi (CEA/MAR/DEN/DMRC/SA2I/L2AT) for her precious advice on the present paper. We would like to thank all CETAMA staff who organized the round robin test. 


\section{Table}

Table 1: Results obtained for the IRMM 49d and U500 CRM

using the total evaporation method with the Triton TIMS. Ref corresponds to the reference value, $U_{\text {ref }}$ corresponds to the uncertainty of the reference value $(\mathrm{k}=2)$ and $U$ corresponds to the total uncertainty $(\mathrm{k}=2)$.

\begin{tabular}{|c|c|c|}
\hline CRM & IRMM 49d & U500 \\
\hline Isotope ratio & ${ }^{240} \mathrm{Pu} /{ }^{242} \mathrm{Pu}$ & ${ }^{235} \mathrm{U} /{ }^{238} \mathrm{U}$ \\
\hline Ref. & 0.046070 & 0.9997 \\
\hline Results & 0.046063 & 1.0001 \\
\hline RSD (\%) & 0.003 & 0.01 \\
\hline Bias (\%) & -0.01 & 0.04 \\
\hline$U_{r e f}(\%)$ & 0.08 & 0.10 \\
\hline$U(\%)$ & 0.08 & 0.11 \\
\hline
\end{tabular}

Table 2: Results obtained on the americium sample using the total evaporation method.

The ${ }^{241} \mathrm{Am} /{ }^{243} \mathrm{Am}$ isotope ratio corresponds to the VG Sector 54 and Triton TIMS average results. The ${ }^{242 \mathrm{~m}} \mathrm{Am} /{ }^{243} \mathrm{Am}$ isotope ratio corresponds to the Triton TIMS average results. Cert. corresponds to the assigned value, $U_{\text {cert }}$ corresponds to the assigned value uncertainty $(\mathrm{k}=2)$ and $U$ corresponds to the total uncertainty $(\mathrm{k}=2)$.

\begin{tabular}{ccc}
\hline Isotope ratio & ${ }^{241} \mathrm{Am} /{ }^{243} \mathrm{Am}$ & ${ }^{242 \mathrm{~m}} \mathrm{Am} /{ }^{243} \mathrm{Am}$ \\
\hline Cert. & 0.136138 & 0.0001373 \\
Results & 0.13614 & 0.0001427 \\
RSD (\%) & 0.04 & 2.2 \\
Bias (\%) & 0.000090 & 4.0 \\
$U_{\text {cert. }}(\%)$ & 0.04 & 1.8 \\
$U(\%)$ & 0.11 & 8.9 \\
\hline
\end{tabular}


Table 3: Americium sample concentration ( $\left.\mu \mathrm{g} \cdot \mathrm{g}^{-1}\right)$ determined by TIMS and isotope dilution. Cert. corresponds to the assigned value, $U_{\text {cert }}$ corresponds to the assigned value uncertainty $(\mathrm{k}=2)$ and $U$ corresponds to the total uncertainty $(\mathrm{k}=2)$.

\begin{tabular}{cc}
\hline Americium sample concentration \\
\hline Cert. & 1.5716 \\
Results & 1.572 \\
RSD (\%) & 0.06 \\
Bias (\%) & 0.019 \\
$U_{\text {cert. }}(\%)$ & 0.19 \\
$U(\%)$ & 0.81 \\
\hline
\end{tabular}




\section{Figure}
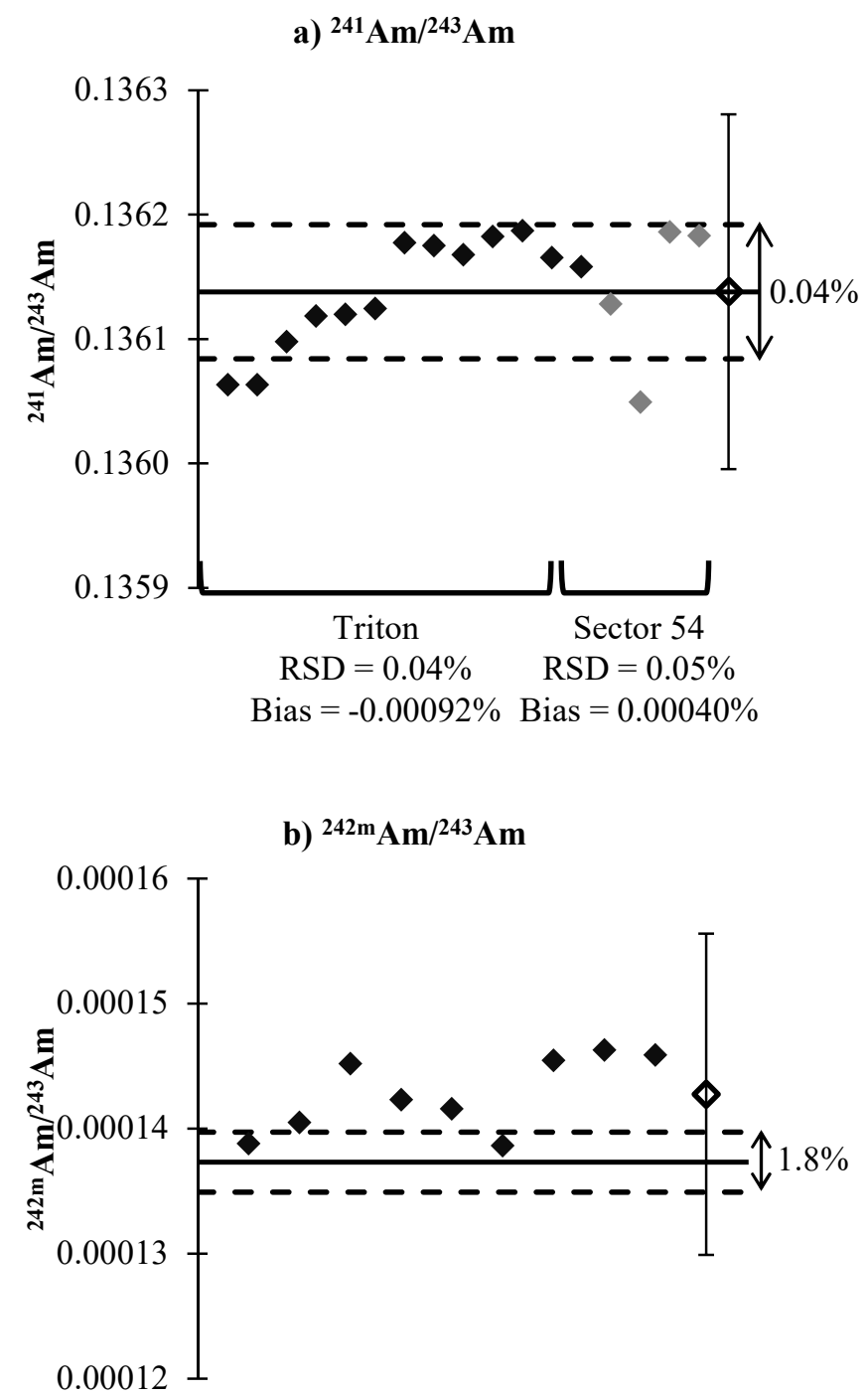

Figure 1: Results for the ${ }^{241} \mathrm{Am} /{ }^{243} \mathrm{Am}$ (a) and ${ }^{242 \mathrm{~m}} \mathrm{Am} /{ }^{243} \mathrm{Am}$ (b) isotope ratio individual measurements (full squares) with the total evaporation method using the Thermo Fisher Triton TIMS $\left({ }^{241} \mathrm{Am} /{ }^{243} \mathrm{Am}\right.$ and ${ }^{242 \mathrm{~m}} \mathrm{Am} /{ }^{243} \mathrm{Am}$ isotope ratios) and the VG Sector 54 TIMS (only ${ }^{241} \mathrm{Am} /{ }^{243} \mathrm{Am}$ isotope ratio). Empty diamonds with error bars represent the series average with its estimated uncertainties at $\mathrm{k}=2$. The dark line (-) corresponds to the assigned value for the ${ }^{241} \mathrm{Am} /{ }^{243} \mathrm{Am}$ and for the ${ }^{242 \mathrm{~m}} \mathrm{Am} /{ }^{241} \mathrm{Am}$ and the dotted line (- - ) represents its uncertainty at $\mathrm{k}=2$ 


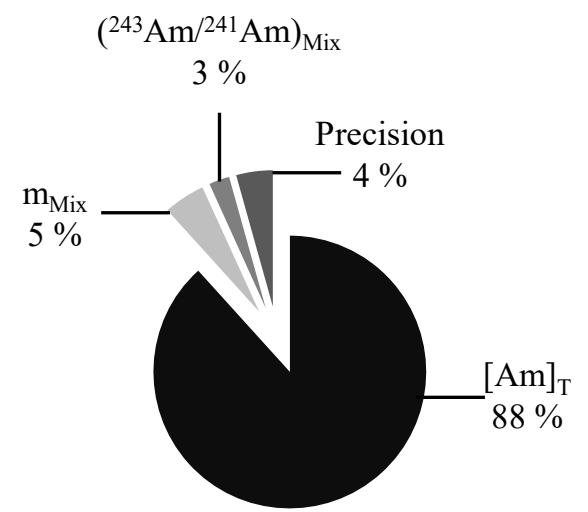

Figure 2: Relative contribution (\%) of the main uncertainty sources for the americium concentration determined by TIMS and isotope dilution 


\section{References}

[1] Henri Becquerel National Laboratory, Mini Table of radionucleides, First edition, EDP Sciences, 2015.

[2] M. Beauvy, G. Berthoud, M. Defranceschi, G. Ducros, Y. Guérin, C. Latgé, Y. Limoge, C. Madic, P. Moisy, G. Santarani, J.-M. Seiler, P. Sollogoub and E. Vernaz, Treatment and recycling of spent nuclear fuel, Actinide partitioning application to waste management, CEA and Ed, France, 2008.

[3] H. Michel, G. Barci-Funel, J. Dalmasso, G. Ardisson, P.G. Appleby, E. Haworth and F. El-Daoushy, Plutonium, americium and cesium records in sediment cores from Blelham Tarn, Cumbria (UK), J. Environ. Radioact. 247 (2001) 107-110.

[4] F. Chartier, M. Aubert and M. Pilier, Determination of Am and Cm in spent nuclear fuels by isotope dilution inductively coupled plasma mass spectrometry and isotope dilution thermal ionization mass spectrometry after separation by highperformance liquid chromatography, Fresenius. J. Anal. Chem. 364 (1999) 320 327.

[5] S.K. Aggarwal, A review on the mass spectrometric studies of americium: present status and future perspective, Mass Spectrom. Rev. (2016).

[6] A. Quemet, M. Maloubier and A. Ruas, Contribution of the Faraday cup coupled to $1012 \mathrm{ohms}$ current amplifier to uranium $235 / 238$ and 234/238 isotope ratio measurements by Thermal Ionization Mass Spectrometry, Int. J. Mass Spectrom. 404 (2016) 35-39.

[7] A. Quemet, M. Maloubier, V. Dalier and A. Ruas, Development of an analysis method of minor uranium isotope ratio measurements using electron multipliers in thermal ionization mass spectrometry, Int. J. Mass Spectrom. 374 (2014) 26-32.

[8] S. Bürger, L.R. Riciputi, D.A. Bostick, S. Turgeon, E.H. McBay and M. Lavelle, Isotope ratio analysis of actinides, fission products, and geolocators by high- 
efficiency multi-collector thermal ionization mass spectrometry, Int. J. Mass Spectrom. 286 (2009) 70-82.

[9] S. Bürger, S.D. Balsley, S. Baumann, J. Berger, S.F. Boulyga, J.A. Cunningham, S. Kappel, A. Koepf and J. Poths, Uranium and plutonium analysis of nuclear material samples by multi-collector thermal ionisation mass spectrometry: Quality control, measurement uncertainty, and metrological traceability, Int. J. Mass Spectrom. 311 (2012) 40-50.

[10] K.L. Ramakumar, M.K. Saxena, V.A. Raman, V.L. Sant, V.D. Kavimandan, B.P. Datta and H.C. Jain, Determination of zirconium in $\mathrm{U}-\mathrm{Zr}-\mathrm{Al}$ and $\mathrm{Pu}-\mathrm{Zr}-\mathrm{Al}$ alloys by isotope dilution thermal ionization mass spectrometry, J. Radioanal. Nucl. Chem. 158 (1992) 13-21.

[11] K. David, J.L. Birck, P. Telouk and C.J. Allègre, Application of isotope dilution for precise measurement of $\mathrm{Zr} / \mathrm{Hf}$ and $176 \mathrm{Hf} / 177 \mathrm{Hf}$ ratios by mass spectrometry (ID-TIMS/ID-MC-ICP-MS), Chem. Geol. 157 (1999) 1-12.

[12] A. Quemet, C. Maillard and A. Ruas, Determination of zirconium isotope composition and concentration for nuclear sample analysis using Thermal Ionization Mass Spectrometry, Int. J. Mass Spectrom. 392 (2015) 34-40.

[13] S.K. Aggarwal, M.K. Saxena, P.M. Shah, S. Kumar and H.C. Jain, Thermal Ionisation Mass Spectrometry for Determination of Uranium and Plutonium : Ion Source Chemistry, Esarda Bull. 26 (n.d.) 17-21.

[14] K.. Ramakumar, R.M. Rao, L. Gnanayyan and H.C. Jain, Simultaneous isotopic analysis of uranium and plutonium by thermal ionisation mass spectrometry coupled to a variable multicollection detection system, Int. J. Mass Spectrom. Ion Process. 134 (1994) 183-190.

[15] K.J. Mathew, G. O'Connor, A. Hasozbek and M. Kraiem, Total evaporation method for uranium isotope-amount ratio measurements, J. Anal. At. Spectrom. 28 (2013) 866-876. 
[16] K.J. Mathew, G.L. Singleton, R.M. Essex, A. Hasozbek, G. Orlowicz and M. Soriano, Characterization of uranium isotopic abundances in depleted uranium metal assay standard 115, J. Radioanal. Nucl. Chem. 296 (2012) 435-440.

[17] A. Trinquier and P. Komander, Precise and accurate uranium isotope analysis by modified total evaporation using $1013 \mathrm{ohm}$ current amplifiers, J. Radioanal. Nucl. Chem. 307 (2016) 1927-1932.

[18] S.K. Aggarwal, Thermal ionisation mass spectrometry (TIMS) in nuclear science and technology - a review, Anal. Methods. 8 (2016) 942-957.

[19] B.D. Poupard and B. Journaux, Determination of Picogram Quantities of Americium and Curium by Thermal Ionization Mass Spectrometry ( TIMS ), Radiochim. Acta. 49 (1990) 25-28.

[20] E. Esbelin, E. Buravand, S. Bejaoui, J. Lamontagne and J.M. Bonnerot, Americium, curium and neodymium analysis in ECRIX-H irradiated pellet: Sample preparation for TIMS measurements, Radiochim. Acta. 101 (2013) $293-$ 300.

[21] M.L. Baruzzini, H.L. Hall, M.G. Watrous, K.J. Spencer and F.E. Stanley, Enhanced ionization efficiency in TIMS analyses of plutonium and americium using porous ion emitters, Int. J. Mass Spectrom. 412 (2016) 8-13.

[22] S.K. Aggarwal, D. Alamelu, P.M. Shah and N.N. Mirashi, Precise and accurate determination of the half-life of the a -decay nuclide 243Am using $241 \mathrm{Am}$ as the reference isotope, Nucl. Instruments Methods Phys. Res. Sect. A. 571 (2007) 663668.

[23] K.J. Mathew and A. Hasozbek, Comparison of mass spectrometric methods (TE, MTE and conventional) for uranium isotope ratio measurements, J. Radioanal. Nucl. Chem. 307 (2016) 1681-1687.

[24] J.C. Dubois, G. Retali and J. Cesario, Isotopic analysis of rare earth elements by total vaporization of samples in thermal ionization mass spectrometry, Int. J. Mass 
Spectrom. Ion Process. 120 (1992) 163-177.

[25] J.M. Koornneef, C. Bouman, J.B. Schwieters and G.R. Davies, Use of 10(12) ohm current amplifiers in $\mathrm{Sr}$ and $\mathrm{Nd}$ isotope analyses by TIMS for application to subnanogram samples, J. Anal. At. Spectrom. 28 (2013) 749.

[26] D. Wielandt and M. Bizzarro, A TIMS-based method for the high precision measurements of the three-isotope potassium composition of small samples, J. Anal. At. Spectrom. 26 (2011) 366.

[27] D. Tuttas, J. Schwieters, N. Quaas, C. Bouman and T.F. Scientific, Improvements in TIMS High Precision Isotope Ratio Measurements for Small Sample Sizes, Thermo Fisher Scientific, Bremen, Germany, (2007) vol. application note: 30136.

[28] M.E. Wieser and J.B. Schwieters, The development of multiple collector mass spectrometry for isotope ratio measurements, Int. J. Mass Spectrom. 242 (2005) 97-115.

[29] J.-H. Park and K. Jeong, Experimental evaluation of the detection methods of thermal ionization mass spectrometry for isotopic analysis of ultra-trace level uranium, Microchem. J. 137 (2018) 334-341.

[30] S. Richter, S. a. Goldberg, P.B. Mason, a. J. Traina and J.B. Schwieters, Linearity tests for secondary electron multipliers used in isotope ratio mass spectrometry, Int. J. Mass Spectrom. 206 (2001) 105-127.

[31] J.M. Koornneef, C. Bouman, J.B. Schwieters and G.R. Davies, Measurement of small ion beams by thermal ionisation mass spectrometry using new $10130 \mathrm{hm}$ resistors, Anal. Chim. Acta. 819 (2014) 49-55.

[32] M. Désenfant and M. Priel, Reference and additional methods for measurement uncertainty evaluation, Measurement. 95 (2017) 339-344.

[33] S. Bürger, R.M. Essex, K.J. Mathew, S. Richter and R.B. Thomas, Implementation of Guide to the expression of Uncertainty in Measurement (GUM) 
to multi-collector TIMS uranium isotope ratio metrology, Int. J. Mass Spectrom. 294 (2010) 65-76.

[34] D.R. Lide, Ionization potentials of atoms and atomic ions, in: Handb. Chem. Phys., 1992: pp. 10-211.

[35] International Atomic Energy Agency, International Target Values 2010 for Measurement Uncertainties in Safeguarding Nuclear Materials - STR368, Vienna, Austria, 2010. 